\title{
A Bibliometric Analysis and Visualisation of Research Trends in Corrosion of Cobalt- Implants
}

\author{
Harjot Singh Gill ${ }^{\mathrm{a}}$ \\ Department of Mechanical Engineering, Chandigarh \\ University,Gharuan,Punjab,India. 140413
}

Article History: Received: 11 January 2021; Accepted: 27 February 2021; Published online: 5 April 2021

\begin{abstract}
Cobalt is one of the most used metals for implants. The bibliometric analysis had been conducted to understand the active authors, organizations, journals, and countries involved in the research domain of "Corrosion of Cobalt-implants". All published articles related to "Corrosion of Cobalt-implants" from "Scopus", were analyzed using the VOS viewer to develop analysis tables and visualization maps. This article had set the objective to consolidate the scientific literature regarding "Corrosion of Cobalt-implants" and also to find out the trends related to the same. The most active journal in this research domain was the Journal of Biomedical Materials Research. The most active country was the United States of America. The leading organization engaged in the research regarding corrosion of Cobalt-implants was the Rush University Medical Center, USA. The most active authors who had made valuable contributions related to Cobalt implants were Hart A.J and Joseph J. J
\end{abstract}

Keywords: Cobalt-implants, Corrosion, Material engineering, Bibliometric analysis, VOS viewer,

\section{Introduction}

An engineered medical device to replace a missing or damaged biological structure is known as an implant. Different types of metals and materials are used to create implants and the most popularly used metals and alloys for bio-implants are stainless steel, cobalt, chromium, etc. The major issues related to Cobalt implants are the toxicity of the metal, failure of cobalt implants, allergy or hypersensitivity, and corrosion of the Cobalt implants. Cobalt is widely used for diversified dental implants (Peterson, McKinney and Pennel, 1978) (Harris and Lossin, 1971); hip implants (Aherwar, Singh and Patnaik, 2016); hip and knee replacements (Aminatun et al., 2014); Wear or corrosion of Cobalt-based hip implants may lead to Systemic arthroprosthetic cobaltism (Gessner et al., 2019). The cobalt-based implants are stronger and have better mechanical properties. Fabrication techniques can be used for enhancing the applicability of Cobalt-based dental implants by developing dental implants having a porous coating (Klawitter, Weinstein and Peterson, 1977)(Ren, Zhu and Chu, 2017). Heat treatments can improve the corrosion resistance of Cobalt-based dental implants (Alexandru et al., 2012). Titanium is one of the widely used metals for dental implants and usage of Cobalt along with Titanium will result in decreased porosity and reduced corrosion (Al-Hasani, 2019). Serious health issues due to corrosion and wear of metal-metal implants based on Cobalt and Chromium (Campbell and Estey, 2013)(Cobb and Schmalzreid, 2006)

Future research can be on research niches of researching on corrosion of Cobalt-based implants, measures for reducing the corrosion of Cobalt-based implants. Issues connected with corrosion and failure of Cobalt-based implants are also equally important. This bibliometric analysis will be a useful platform for future researchers by realizing the top researchers, organizations, and countries involved in research regarding bio-implants. This article is arranged into four sections. The first section is the introduction, followed by the discussion of the methodology by which the research was conducted. The third section deals with results and discussion. The fourth section deals with the conclusion. The following research objectives and research questions were framed for conducting bibliometric analysis systematically.

\subsection{Research Objectives}

a) To consolidate the literature regarding corrosion of Cobalt-implants

b) To find out the trends related to research in corrosion of Cobalt-implants

\subsection{Research Questions}

a) Who are the active researchers working on corrosion of Cobalt-implants?

b) Which are the main organizations and countries working on corrosion of Cobalt-implants?

c) Which are the main journals corrosion of Cobalt-implants?

\section{Research Methodology}

Scopus files had been used for this article. For the article selection, the Boolean used was TITLE-ABS (Corrosion Cobalt implants) on 10/03/2021. All the tables in this paper were created by using Microsoft Excel and VOS Viewer. Grammarly was used for spelling and grammar checks. Mendeley was used for article review and citation. This paper had been inspired by bibliometric analysis in its presentation style, analysis, and methodology 
from the works (Farhat et al., 2013; Liao et al., 2016; Kolkailah et al., 2019; Rodríguez-Padial et al., 2019; Tran et al., 2019; Ullah et al., 2019; Shahid et al., 2020).

\section{Results and discussion}

\subsection{Results}

This first round of search produced an outcome of 483 documents, in ten languages, out of which 458 documents were in English. The classification of document categories is shown in Figure 1. For improving the quality of the analysis, we had selected only the peer-reviewed articles and all other documents had not been considered. Thus after using filters "Article" and "English" the second round search produced an outcome of 330 English articles (both open access and others) and had been used to conduct bibliometric analysis and visualization using VOS Viewer. The English research articles in this domain since 1969 had been shown in Figure 2.

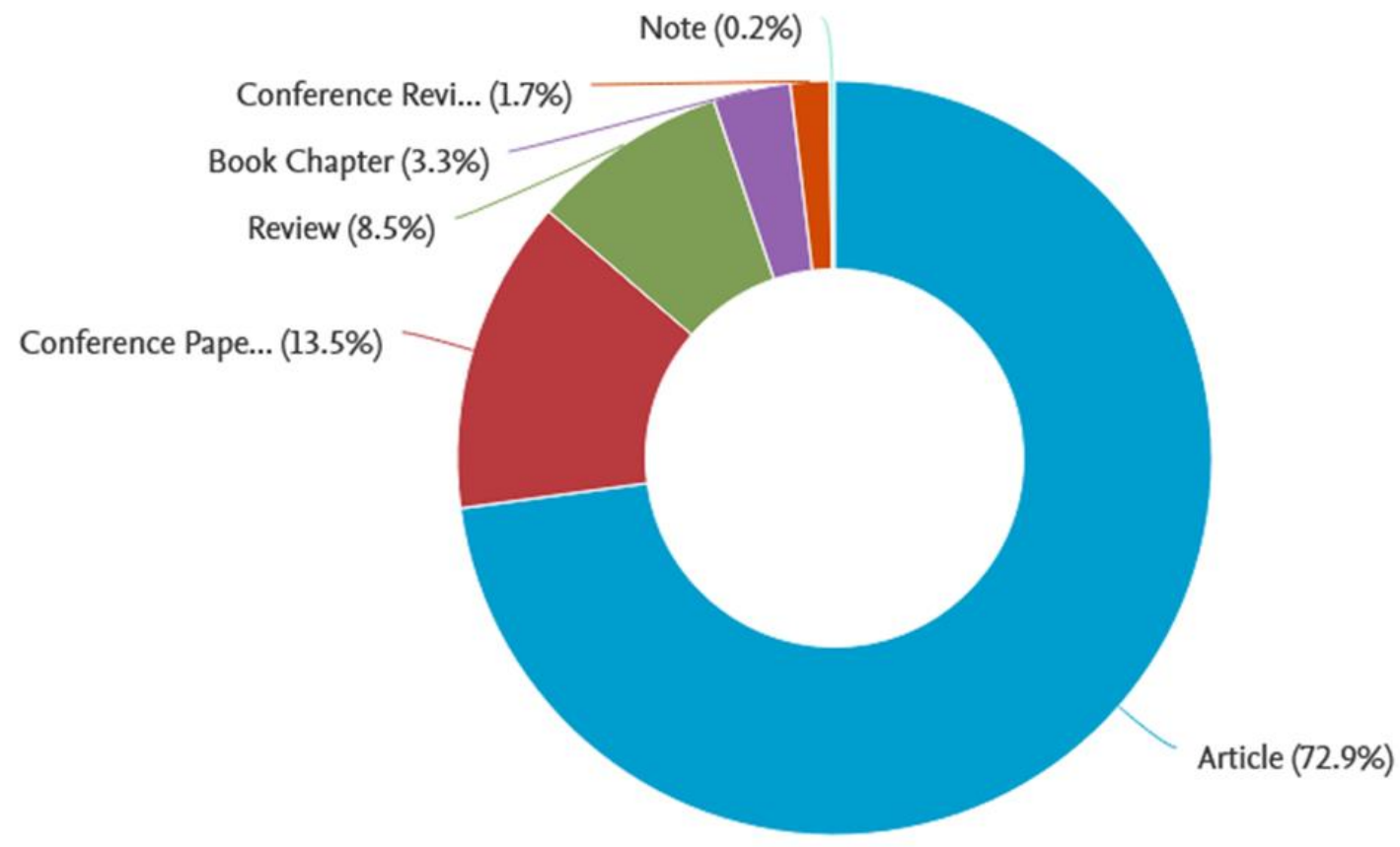

Figure 1: Classification of the documents on "Corrosion of Cobalt implants", Source: www.scopus.com

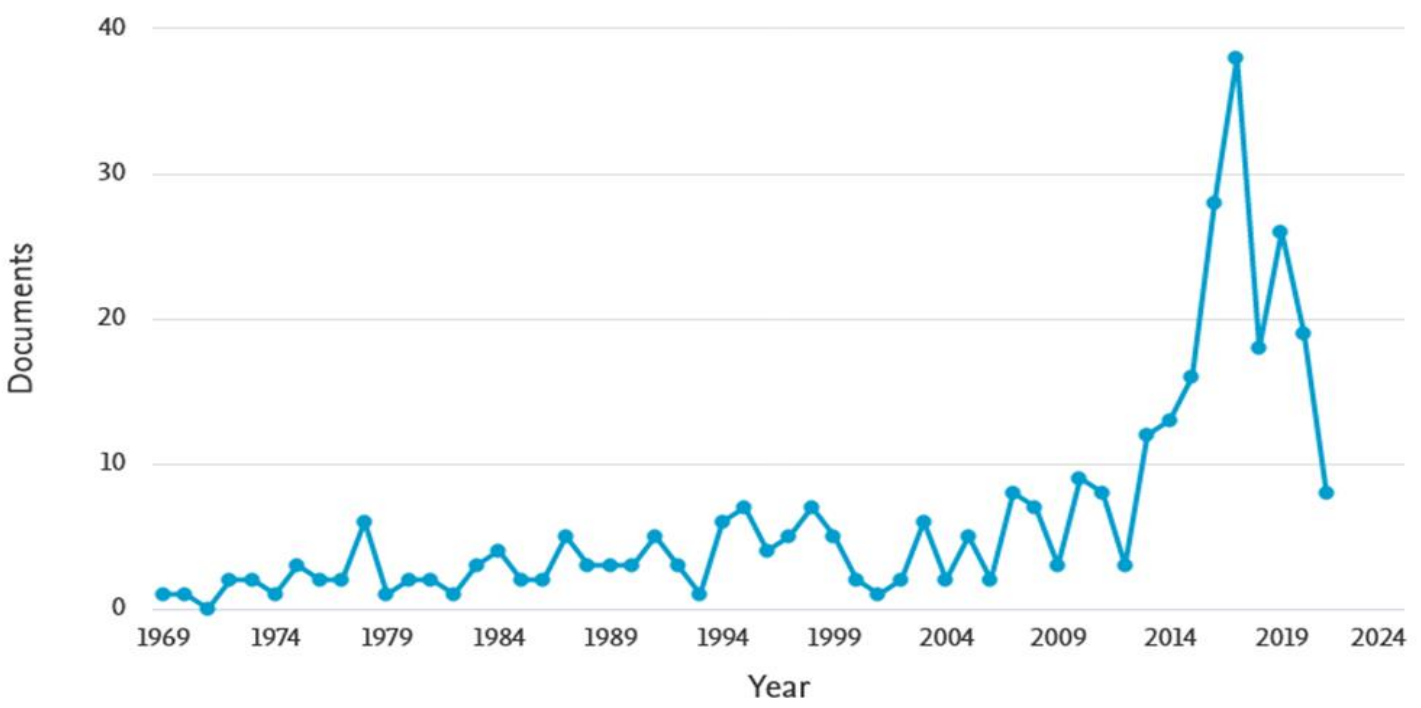

Figure 2: Period wise publication of articles, Source: WWW.scopus.com

Co-authorship analysis of top authors had been shown in figure 3. For a better presentation of the analysis, the parameters used were the minimum number of documents of an author as four and the minimum number of citations of authors as one. This combination plotted the map of thirty authors, in twelve clusters. The overlay visualization map of co-authorship analysis plotted in Figure 3, points out the major researchers with their strong co-authorship linkages and clusters involved. 


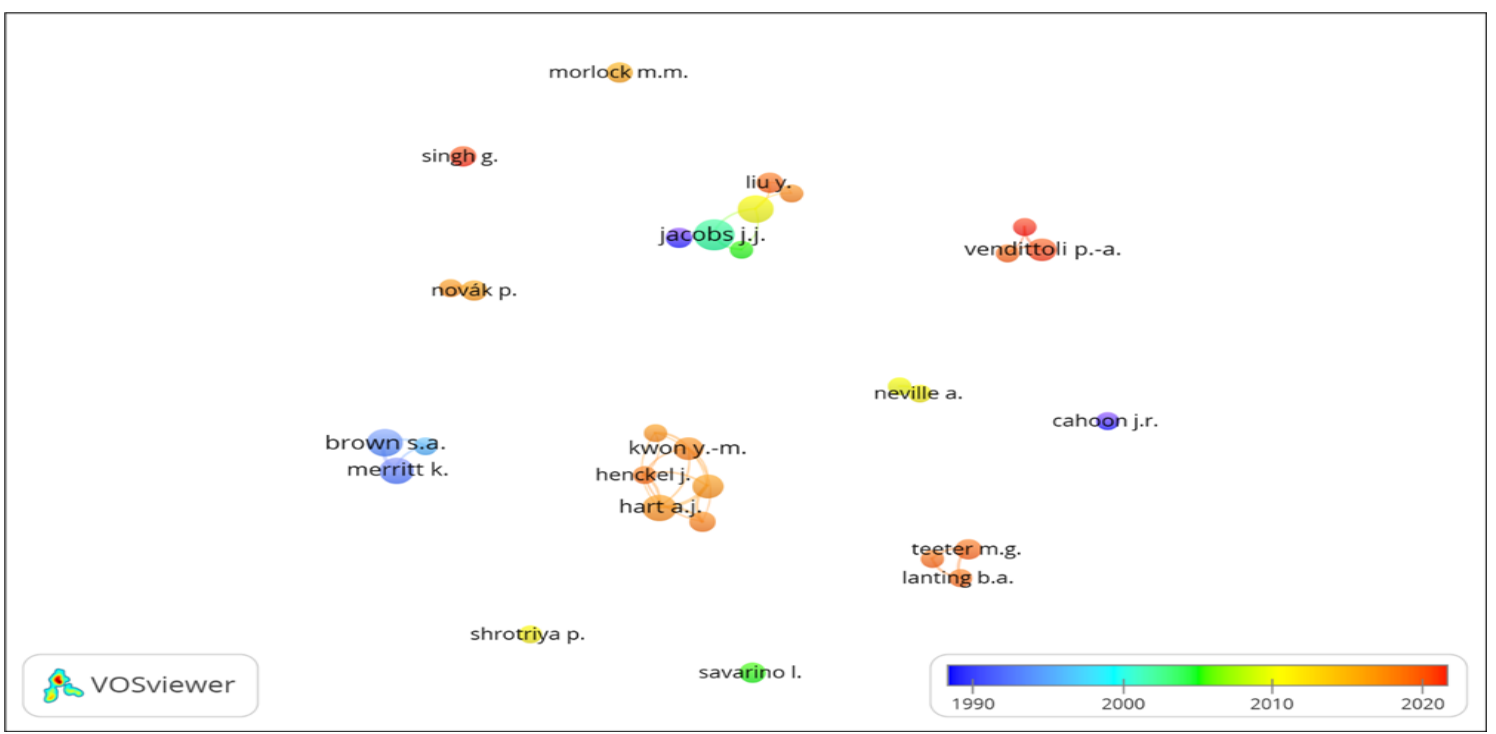

Figure 3: Co-authorship analysis on basis of authors

The citation analysis of top authors had been shown in table 1, along with co-authorship links. For the citation analysis, the parameters used were the minimum number of documents of an author as one and the minimum citations of an author as one

Table 1: Highlights of most active authors

\begin{tabular}{|c|r|r|r|r|r|}
\hline Description & Authors & Documents & Citations & $\begin{array}{c}\text { Average } \\
\text { citations per } \\
\text { documents }\end{array}$ & $\begin{array}{c}\text { Link } \\
\text { strength }\end{array}$ \\
\hline $\begin{array}{l}\text { Authors with the } \\
\text { highest publication } \\
\text { and citation }\end{array}$ & Jacobs J.J & 11 & 1910 & 172.7 & 42 \\
\hline $\begin{array}{l}\text { Authors with the } \\
\text { highest co-authorship } \\
\text { links }\end{array}$ & Hart A.J & 8 & 145 & 18.1 & 59 \\
\hline
\end{tabular}

In Co-occurrence analysis, we had used all keyword analyses, by keeping the minimum number of occurrences of a keyword as 40. This combination plotted the map of 30 thresholds, in two clusters. The overlay visualization of co-occurrence analysis of keywords has been shown in Figure 4.

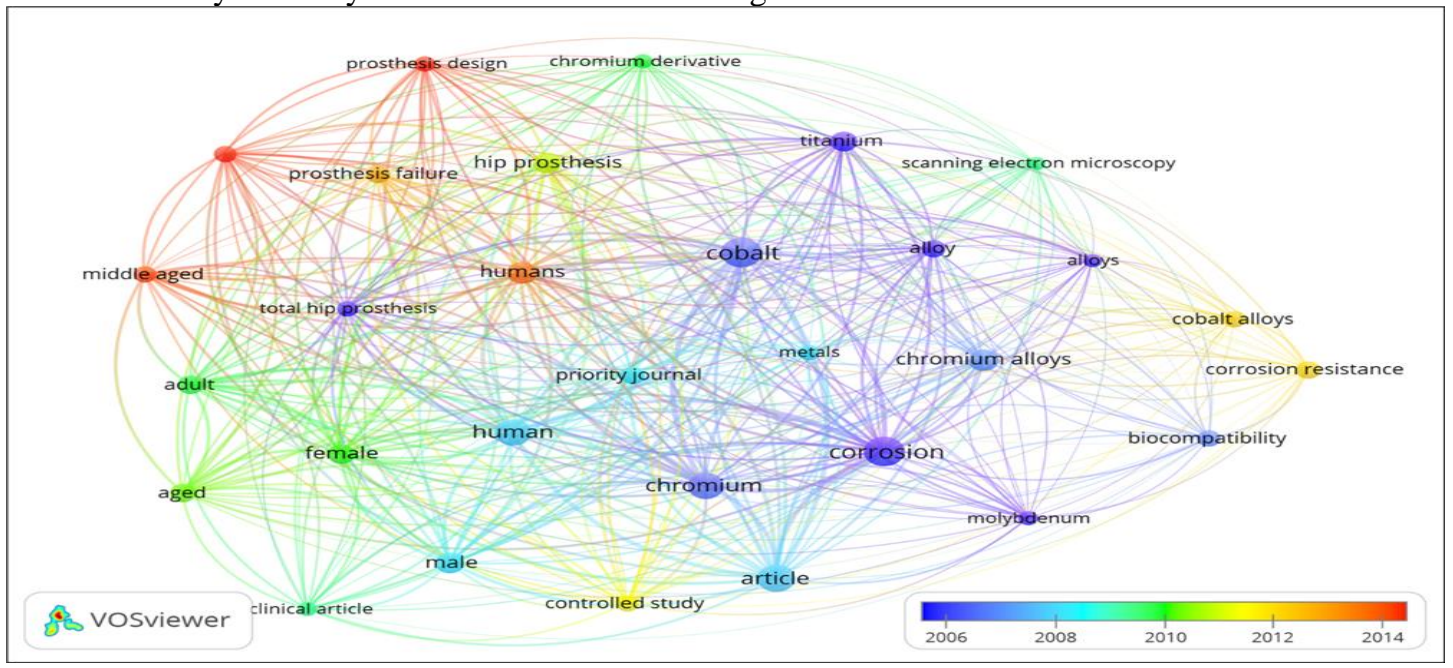

Figure 4: Co-occurrence analysis on basis of all keywords

The leading organizations engaged in research on "corrosion of Cobalt-implants" had been found out by the volume of publications and citation analysis, the parameters used are the minimum number of documents of an organization as one and the minimum number of citations of organizations as one. The leading organization in the research regarding "corrosion of Cobalt-implants", with the highest number of publications and citations, was the Rush University Medical center of the United States of America (Refer to table 2).

Table 2: Highlights of the most active organization 


\begin{tabular}{|c|c|c|c|c|}
\hline Organizations & Country & s & Document & $\begin{array}{c}\text { Citatio } \\
\text { Average } \\
\text { Citations } \\
\text { per } \\
\text { document }\end{array}$ \\
\hline Rush University Medical Center & $\begin{array}{c}\text { United States } \\
\text { of America }\end{array}$ & 15 & 1940 & 129.3 \\
\hline
\end{tabular}

Co-authorship analysis of the countries engaged in the research on "corrosion of Cobalt-implants" had been shown in Figure 5. The overlay visualization map of co-authorship analysis plotted in Figure 5, points out the main countries with their strong co-authorship linkages and clusters involved.

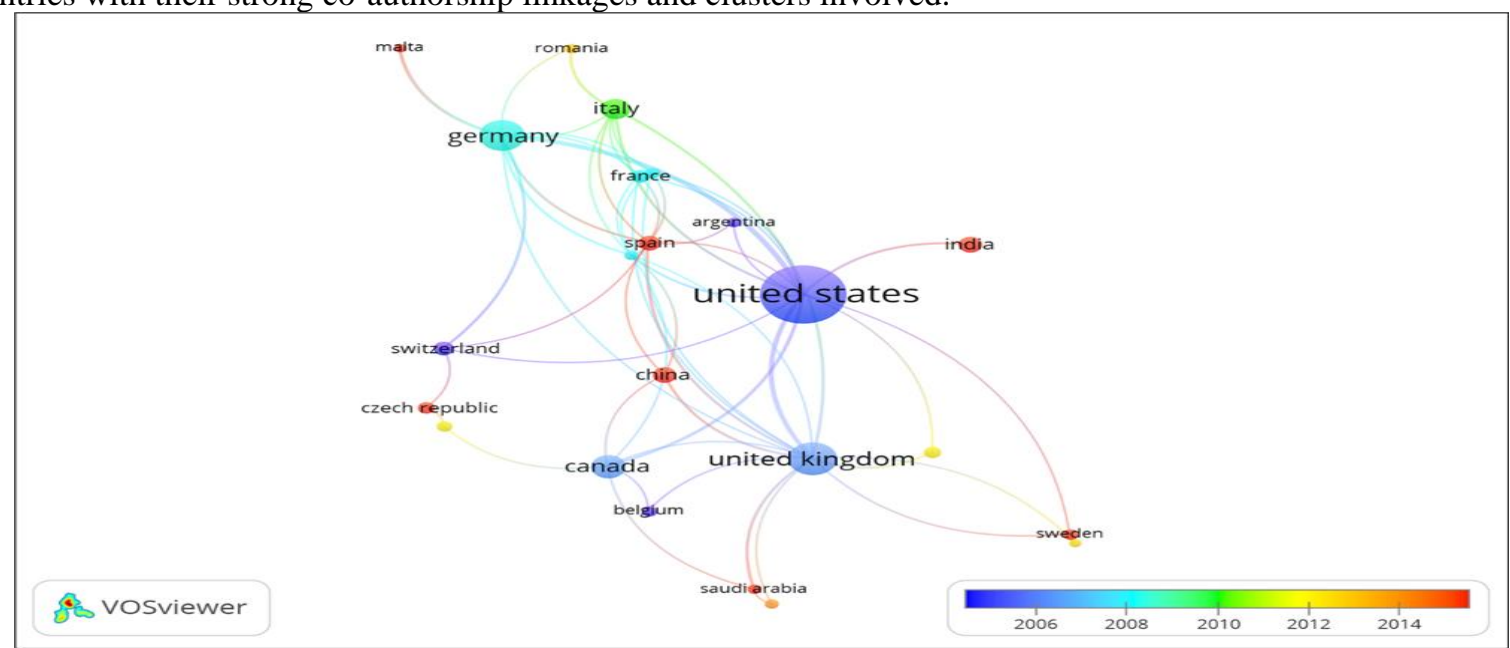

Figure 5: Co-authorship analysis on basis of countries

The citation analysis of top countries had been shown in table 3, along with co-authorship links. For the citation analysis, the parameters used were the minimum number of documents of a country as one and the minimum citations of the country as one.

Table 3: Highlights of Active Countries

\begin{tabular}{|c|c|c|c|c|}
\hline Description & Country & Documen & Citation & Link strength \\
\hline $\begin{array}{c}\text { The country with the } \\
\text { publication, } \\
\text { highest } \\
\text { citations, and co-authorship } \\
\text { links }\end{array}$ & $\begin{array}{c}\text { United States of } \\
\text { America }\end{array}$ & 136 & & \\
\hline
\end{tabular}

The most active country in this research domain was the United States of America, with the highest number of publications, co-authorship links, and citations.

Link analysis and citation analysis were used to identify the most active journal in this research domain. We have taken the parameters of the minimum number of documents of a journal as one and the minimum number of citations of a journal as one for the link analysis and citation analysis. Highlights of the most active and relevant journals related to "corrosion of Cobalt-implants" are shown in table 4 . Table 4 shows the journal activity of this research domain through parameters of publication volume, citations, and co-authorship linkages.

Table 4: Analysis of journal activity

\begin{tabular}{|c|c|r|r|r|}
\hline Description & Journal details & Documents & Citations & $\begin{array}{l}\text { Average } \\
\text { citations } \\
\text { per } \\
\text { documents }\end{array}$ \\
\hline $\begin{array}{l}\text { Journal with the } \\
\text { highest publications, } \\
\text { citations, and co- } \\
\text { authorship links }\end{array}$ & $\begin{array}{c}\text { Journal } \\
\text { Biomedical } \\
\text { Materials Research }\end{array}$ & 29 & 2212 & \\
\hline
\end{tabular}

From the above discussion regarding the bibliometric patterns in the research regarding corrosion of Cobaltimplants, this research had observed a gradual increase in research interest regarding corrosion of Cobalt implants from the starting of the millennium and the momentum is going on positively. This points out the relevance and potential of this research domain (Refer to Figure 2). The most active authors in this research domain were the Hart A.J and Jabob J. J with the highest citations; highest publication and co-authorship links; respectively (Refer to table 1). The overlay analysis of top countries researching corrosion of Cobalt implantations indicates that the United States of America was the leading country relating to the highest number of publications, citations, and co- 
authorship links (Refer to figure 5). The top journal of this research domain was identified as the Journal of Biomedical Materials Research from these wide sources of information, researchers can focus on top journals where they can identify the most relevant and highly cited articles regarding Corrosion of Cobalt-implants.

\section{Conclusion}

Cobalt implant was an interesting research domain and the most active journal related to this research domain was the Journal of Biomedical Materials Research. The most active country was the United States of America. The leading organization engaged in the research regarding corrosion of Cobalt-implants was the Rush University Medical Center, USA. The most active authors who had made valuable contributions related to Cobalt implants were Hart A.J and Joseph J. J with the highest citations; and publication and co-authorship links citations respectively. This research domain offers a new avenue for researchers and future research can be on innovations in corrosion of Cobalt-implants.

\section{References}

1. Aherwar, A., Singh, A. K. and Patnaik, A. (2016) 'Cobalt-based alloy: A better choice biomaterial for hip implants', Trends in Biomaterials and Artificial Organs. Society for Biomaterials and Artificial Organs - India, 30(1), pp. 50-55. Available at: https://www.scopus.com/inward/record.uri?eid=2-s2.0 85026653857\&partnerID=40\&md5=885d77ec571ca5cc9d84f288e282ef3f.

2. Al-Hasani, F. J. (2019) 'Studying the effect of cobalt percentage on the corrosion rate of sintered titanium dental implants', in Haider A.J. Jabur A.R., S. C.-T. V. G. (ed.) AIP Conference Proceedings. American Institute of Physics Inc. doi: 10.1063/1.5138497.

3. Amato, L. E. et al. (2005) 'Electrochemical characterization of sol-gel hybrid coatings in cobalt-based alloys for orthopaedic implants', Materials Letters, 59(16), pp. 2026-2031. doi: 10.1016/j.matlet.2005.02.010.

4. Aminatun et al. (2014) 'Synthesis of cobalt alloy through smelting method and its characterization as prosthesis bone implant', in Djamal M. Mufti N., D. M. (ed.) AIP Conference Proceedings. American Institute of Physics Inc., pp. 137-143. doi: 10.1063/1.4897123.

5. De França, D. G. B. et al. (2015) 'Influence of CAD/CAM on the fit accuracy of implant-supported zirconia and cobalt-chromium fixed dental prostheses', Journal of Prosthetic Dentistry. Mosby Inc., 113(1), pp. 22-28. doi: 10.1016/j.prosdent.2014.07.010.

6. Farhat, T. et al. (2013) 'Research in congenital heart disease: A comparative bibliometric analysis between developing and developed countries', Pediatric Cardiology, 34(2), pp. 375-382. doi: 10.1007/s00246-012-0466-6.

7. Harris, R. and Lossin, C. (1971) 'The use of cobalt chromium alloy and titanium endosseous dental implants', Australian Dental Journal, 16(2), pp. 94-108. doi: 10.1111/j.1834-7819.1971.tb02312.x.

8. Klawitter, J. J., Weinstein, A. M. and Peterson, L. J. (1977) 'Fabrication and Characterization of PorousRooted Cobalt-Chromium-Molybdenum (Co-Cr-Mo) Alloy Dental Implants', Journal of Dental Research, 56(5), pp. 474-480. doi: 10.1177/00220345770560050501.

9. Kolkailah, A. A. et al. (2019) 'Bibliometric Analysis of the Top 100 Most Cited Articles in the First 50 Years of Heart Transplantation', American Journal of Cardiology. Elsevier Inc., 123(1), pp. 175-186. doi: 10.1016/j.amjcard.2018.09.010.

10. Liao, J. et al. (2016) 'The most cited articles in coronary heart disease: A bibliometric analysis between 1970 and 2015', International Journal of Cardiology. Elsevier Ireland Ltd, 222, pp. 1049-1052. doi: 10.1016/j.ijcard.2016.08.002.

11. Lin, W.-S. et al. (2020) 'CAD-CAM cobalt-chromium surgical template for static computer-aided implant surgery: A dental technique', Journal of Prosthetic Dentistry. Mosby Inc., 123(1), pp. 42-44. doi: 10.1016/j.prosdent.2019.04.014.

12. Peterson, L. J., McKinney, R. V and Pennel, B. M. (1978) 'Two year evaluation of perous rooted cobaltchromium dental implants', Journal of Dental Research, 57(spec. A), p. No. 734. Available at: https://www.scopus.com/inward/record.uri?eid=2-s2.0$0017838402 \&$ partnerID=40\&md5=89e4104671aeb76d00dbdc2bfa368535.

13. Ren, F., Zhu, W. and Chu, K. (2017) 'Fabrication and evaluation of bulk nanostructured cobalt intended for dental and orthopedic implants', Journal of the Mechanical Behavior of Biomedical Materials. Elsevier Ltd, 68, pp. 115-123. doi: 10.1016/j.jmbbm.2017.01.039.

14. Rodríguez-Padial, L. et al. (2019) 'Trends and Bibliometric Impact of Research Grants of the Spanish Society of Cardiology/Spanish Heart Foundation (2007-2012) [Evolución e impacto bibliométrico de las becas de la Sociedad Española de Cardiología/Fundación Española del Corazón en el periodo 2007 2012]', Revista Espanola de Cardiologia. Ediciones Doyma, S.L., 72(12), pp. 1012-1019. doi: 10.1016/j.recesp.2018.08.013.

15. Shahid, I. et al. (2020) 'Characteristics of highly cited articles in heart failure: A bibliometric analysis', Future Cardiology. Future Medicine Ltd., 16(3), pp. 189-197. doi: 10.2217/fca-2019-0016. 
16. Tran, B. X. et al. (2019) 'The current research landscape of the application of artificial intelligence in managing cerebrovascular and heart diseases: A bibliometric and content analysis', International Journal of Environmental Research and Public Health. MDPI AG, 16(15). doi: 10.3390/ijerph16152699.

17. Ullah, S. et al. (2019) 'Publication trends of Pakistan Heart Journal: A bibliometric study', Library Philosophy and Practice. University of Idaho Library, 2019. Available at: https://www.scopus.com/inward/record.uri?eid=2-s2.0-

85072911351\&partnerID=40\&md5=c7b4ec3c78fbd1fed8e2e7890fdef688. 